\title{
Research article \\ Comparison of hematological parameters in mild and severe COVID-19 infected patients: A retrospective observational study
}

\author{
Tania Eltrida Pinto ${ }^{1}$, Rithesh Joseph D'Cunha ${ }^{2}$, Shannon Fernandes ${ }^{3}$, Nireeksha ${ }^{4}$, Gurumurthy T. ${ }^{5}$ \\ ${ }^{1}$ PG Student, ${ }^{2}$ Assistant Professor, ${ }^{5}$ Associate Professor, Department of Anesthesiology, ${ }^{3}$ Assistant Professor, Department of \\ OBG, Father Muller Medical College, Mangalore, Karnataka, India \\ ${ }^{4}$ Lecturer, Department of Conservative Dentistry, AB Shetty Memorial Institute of Dental Sciences, NITTE (Deemed to be) \\ University, Deralakatta, Mangalore, Karnataka, India
}

(Received: August $2021 \quad$ Revised: November $2021 \quad$ Accepted: December 2021)

Corresponding author: Rithesh Joseph D'Cunha. Email: ritheshcold@fathermuller.in

\begin{abstract}
Introduction and Aim: With the coronavirus disease 2019 (COVID-19) pandemic raging on, there is a need to identify clinical and laboratory predictors which predict progression towards severe and fatal forms of this illness. Our study aims to evaluate the ability of hematologic and biochemical biomarkers to discriminate between patients with and without severe or fatal forms of COVID-19.
\end{abstract}

Materials and Methods: A retrospective study was conducted on 200 Covid positive patients;100 with mild disease and 100 with severe disease. Medical records were reviewed to collect demographic data and results of the following blood investigations were noted at admission: $\mathrm{Hb}$, Platelet count, Total and Differential leukocyte count, CRP, AST, ALT, LDH, Ferritin and D-Dimer. Comparative analysis was performed between the 2 groups.

Results: A significant difference in the basophil count (mean 2.35 and 5.92) among those with mild and severe disease respectively was noted as also with the eosinophil count (mean 6.88 and 1.79). The levels of CRP were higher in those with severe disease as compared to the mild disease group (mean 276.29 and 65.23). Ferritin levels were markedly increased severe disease patients (mean 1275.66 and 533.94). D-dimer was markedly increased in COVID-19 patients with severe disease (mean $3813.91 \mathrm{ng} / \mathrm{ml}$ ) compared to those with mild disease group (mean $521.78 \mathrm{ng} / \mathrm{ml})$.

Conclusion: Hematological and biochemical markers positively correlate to the severity of covid infection, thus highlighting their role in the early diagnosis of the disease and can act as independent markers in predicting severity and prognosis of disease.

Keywords: COVID-19; hematological parameters; severity.

\section{INTRODUCTION}

$\mathrm{C}$ OVID 19 has been declared as a pandemic by WHO. Since it has the potential to spread during the incubation period, early diagnosis and management is the key (1). This virus affects people of all age groups. However, data from around the world has shown a higher affection of the middle and older age groups with an age range of 65-85 years (2). Coronavirus has slightly increased gender affinity towards males as compared to females globally (3-5). Patients with SARS-CoV-2 infection can experience a range of clinical manifestations, from no symptoms to critical illness. Based on the severity of illness, adults with SARSCoV-2 infection can be grouped into the following categories (6).

* Asymptomatic or Pre-symptomatic Infection: Individuals with no symptoms of COVID-19 but who test positive for SARS-CoV-2 using a virologic test.

* Mild Illness: Patients presenting with signs and symptoms of COVID-19 like fever, cough, sore throat, malaise, headache, muscle pain, nausea, vomiting, diarrhea, loss of taste and smell but who do not have shortness of breath, dyspnoea, or abnormal chest imaging.

* Moderate Illness: Patients with evidence of lower respiratory disease during clinical assessment or imaging and who have an oxygen saturation $\left(\mathrm{SpO}_{2}\right) \geq 94 \%$ on room air at sea level.

* Severe Illness: Patients who have $\mathrm{SpO}_{2}<94 \%$ on room air at sea level, a ratio of arterial partial pressure of oxygen to fraction of inspired oxygen $\left(\mathrm{PaO}_{2} / \mathrm{FiO}_{2}\right)<300$, respiratory frequency $>30$ breaths/min, or lung infiltrates $>50 \%$.

* Critical Illness: Individuals who have respiratory failure, septic shock, and/or multiple organ dysfunction.

Patients present with varied symptoms present at the onset of infection; fever (98.6\%), fatigue (69.6\%), dry cough $(59.4 \%)$, muscle pain $(34.8 \%)$, dyspnea $(31.2 \%)$, and least frequently with headache $(6.5 \%)$, dizziness $(9.4 \%)$, abdominal pain $(2.2 \%)$, diarrhea $(10.1 \%)$, nausea $(10.1 \%)$ and vomiting (3.6\%; (5). Laboratory abnormalities in Covid affected individuals include lymphocytopenia (82.3\%), thrombocytopenia (36.2\%), leukopenia (33.7\%). Majority of patients reported high levels of C- 
reactive protein (CRP), less frequent were high levels of alanine transaminase (ALT), aspartate aminotransferase (AST), creatine kinase (CK) and Ddimer (7). Due to the lack of evidence on the relationship between hematological parameters and the severity of COVID-19, this study was designed aiming to investigate hematological parameters associated with the severity of the disease in patients with COVID-19 and to determine if these hematological parameters could potentially act as an independent factor and affect the disease prognosis. Objective of the study was to evaluate hematological parameters with respect to severity of illness and identify prognostic significance of these hematological parameters.

\section{METHODOLOGY}

This retrospective observational study was conducted at a tertiary care teaching hospital over a period of 4 months after prior ethical clearance. Patients were divided into 2 groups: mild group comprised those who were RT-PCR COVID positive but with mild symptoms, admitted in the ward and not requiring ICU admission or invasive/noninvasive ventilation. The other group was the severe group comprising those who were RT-PCR COVID positive but with symptoms warranting ICU admission. The categorization of patients was based on the New Coronavirus Pneumonia Prevention and Control Program in China (6), which classified COVID-19 affected patient into four types including mild, moderate, severe, and critical. In our study, severe or critical COVID-19 patients were grouped as severe group, and mild or moderate COVID-19 patients were grouped as the non-severe/mild group.

\section{Inclusion criteria}

* All patients who were admitted with positive real time reverse transcriptase polymerase chain reaction.

* All severe covid positive patients admitted to the ICU.

Table 1: Age distribution of cases

\begin{tabular}{|c|c|c|c|c|c|}
\hline & & & \multicolumn{2}{|c|}{ Group } & \multirow[t]{2}{*}{ Total } \\
\hline & & & Severe & Mild & \\
\hline \multirow[t]{14}{*}{ age } & \multirow[t]{2}{*}{20 and below } & Count & 2 & 3 & 5 \\
\hline & & $\%$ Within Group & $2.0 \%$ & $3.0 \%$ & $2.5 \%$ \\
\hline & \multirow[t]{2}{*}{$21-30$} & Count & 5 & 12 & 17 \\
\hline & & $\%$ Within Group & $5.0 \%$ & $12.0 \%$ & $8.5 \%$ \\
\hline & \multirow[t]{2}{*}{$31-40$} & Count & 5 & 7 & 12 \\
\hline & & \% Within Group & $5.0 \%$ & $7.0 \%$ & $6.0 \%$ \\
\hline & \multirow[t]{2}{*}{$41-50$} & Count & 18 & 17 & 35 \\
\hline & & $\%$ Within Group & $18.0 \%$ & $17.0 \%$ & $17.5 \%$ \\
\hline & \multirow[t]{2}{*}{$51-60$} & Count & 23 & 29 & 52 \\
\hline & & $\%$ Within Group & $23.0 \%$ & $29.0 \%$ & $26.0 \%$ \\
\hline & \multirow[t]{2}{*}{$61-70$} & Count & 24 & 20 & 44 \\
\hline & & $\%$ Within Group & $24.0 \%$ & $20.0 \%$ & $22.0 \%$ \\
\hline & \multirow[t]{2}{*}{ Above 70} & Count & 23 & 12 & 35 \\
\hline & & $\%$ Within Group & $23.0 \%$ & $12.0 \%$ & $17.5 \%$ \\
\hline \multirow{2}{*}{\multicolumn{2}{|c|}{ Total }} & Count & 100 & 100 & 200 \\
\hline & & $\%$ Within Group & $100.0 \%$ & $100.0 \%$ & $100.0 \%$ \\
\hline
\end{tabular}

* All covid positive patients with mild disease who were admitted to the ward

* Age group of 18-80 years with or without comorbidities

\section{Exclusion criteria}

* Patients with mild covid disease admitted in the ward if shifted to ICU during hospital stay due to worsening of symptoms. Age less than 18 years and more than 80 years.

* Medical records were reviewed to collect the information on patient's demographics, symptoms and presence or absence of any comorbidities.

* The results of the blood samples which were collected at admission were analyzed. Laboratory tests done subsequently were not considered. The following bio markers were analyzed: white blood cell count, platelet count, lymphocyte count $(\times 109 / \mathrm{L})$, neutrophil granulocyte count ( $\times 109 / \mathrm{L})$, C-reactive protein level (in milligrams per liter), lactate dehydrogenase level (LDH) (in international units per liter), ferritin, D-dimer, and liver enzymes.

* The hematological parameters of both mild and severe covid positive were compared to determine its association with severity of disease.

\section{Statistical analysis}

The collected data was summarized by frequency, percentage, mean, standard deviation, median and IQR. Comparison of blood parameters between severe and non-severe patients was performed by Chi-square test and Mann Whitney test. Optimal cut off was obtained by ROC.

\section{RESULTS}

This retrospective, observational study was conducted on 200 COVID positive patients admitted in Father Muller Medical College, Mangalore. One hundred patients had mild disease and other 100 had severe disease and comparison was done between the 2 groups. 
Chi square test $\mathrm{p}=0.241$, NS

The younger population has milder disease and the older population had severe disease. The difference, however, was not statistically significant (Table 1).

Table 2: Gender distribution of cases

\begin{tabular}{|c|c|c|c|c|c|}
\hline \multicolumn{2}{|c|}{} & \multicolumn{2}{c|}{ Group } & \multirow{2}{*}{ Total } \\
\cline { 4 - 6 } & & severe & Mild & \\
\hline \multirow{3}{*}{ sex } & \multirow{2}{*}{$\mathrm{F}$} & Count & 33 & 39 & 72 \\
\cline { 3 - 6 } & & \% Within Group & $33.0 \%$ & $39.0 \%$ & $36.0 \%$ \\
\cline { 3 - 6 } & \multirow{2}{*}{$\mathrm{M}$} & Count & 67 & 61 & 128 \\
\cline { 3 - 6 } & & $\%$ Within Group & $67.0 \%$ & $61.0 \%$ & $64.0 \%$ \\
\hline \multicolumn{2}{|c|}{ Total } & Count & 100 & 100 & 200 \\
\cline { 2 - 6 } & & \% Within Group & $100.0 \%$ & $100.0 \%$ & $100.0 \%$ \\
\hline
\end{tabular}

Chi square test $\mathrm{p}=0.376$, NS

There was no statistical significance between males and females in terms of severity of the disease (Table 2).

Table 3: Hematological parameters

\begin{tabular}{|c|c|c|c|c|c|c|c|c|}
\hline \multicolumn{2}{|c|}{ Group } & \multirow{2}{*}{$\begin{array}{c}\mathbf{n} \\
100\end{array}$} & \multirow{2}{*}{\begin{tabular}{c|} 
Mean \\
12.01 \\
\end{tabular}} & \multirow{2}{*}{$\begin{array}{c}\begin{array}{r}\text { Standard } \\
\text { Deviation }\end{array} \\
2.33 \\
\end{array}$} & \multirow{2}{*}{$\begin{array}{c}\text { Median } \\
12.00 \\
\end{array}$} & \multirow{2}{*}{$\begin{array}{c}\mathrm{IQR} \\
11-14\end{array}$} & \multirow{2}{*}{$\begin{array}{c}\begin{array}{c}\text { Mann } \\
\text { Whitney test } \\
\text { P value }\end{array} \\
0.303 \\
\end{array}$} & \multirow[b]{2}{*}{$\mathrm{NS}$} \\
\hline \multirow[t]{2}{*}{$\mathrm{HB}$} & severe & & & & & & & \\
\hline & Mild & 100 & 11.79 & 2.29 & 12.00 & $10-13$ & & \\
\hline \multirow[t]{2}{*}{ TC } & severe & 100 & 8970.20 & 3936.01 & 9000.00 & $6225-11450$ & \multirow[t]{2}{*}{0.207} & \multirow[t]{2}{*}{ NS } \\
\hline & Mild & 100 & 8741.49 & 5137.86 & 7650.00 & $4800-11700$ & & \\
\hline \multirow[t]{2}{*}{$\mathrm{PC}$} & severe & 100 & 239900.00 & 113764.55 & 220000.00 & $170000-290000$ & \multirow[t]{2}{*}{0.728} & \multirow[t]{2}{*}{ NS } \\
\hline & Mild & 100 & 247190.00 & 119960.83 & 230000.00 & $177250-294000$ & & \\
\hline \multirow[t]{2}{*}{$\mathrm{N}$} & severe & 100 & 74.89 & 14.00 & 76.50 & $68.25-85$ & \multirow[t]{2}{*}{0.143} & \multirow[t]{2}{*}{ NS } \\
\hline & Mild & 100 & 72.59 & 12.90 & 75.00 & $65.25-80.75$ & & \\
\hline \multirow[t]{2}{*}{$\mathrm{L}$} & severe & 100 & 15.72 & 9.15 & 14.00 & $8-21.75$ & \multirow[t]{2}{*}{0.263} & \multirow[t]{2}{*}{ NS } \\
\hline & Mild & 100 & 17.84 & 10.97 & 14.50 & $10-25$ & & \\
\hline \multirow[t]{2}{*}{ B } & severe & 100 & 5.92 & 2.98 & 6.00 & $4-8.75$ & \multirow[t]{2}{*}{0.000} & \multirow[t]{2}{*}{ HS } \\
\hline & Mild & 100 & 2.35 & 3.41 & 1.00 & $1-2$ & & \\
\hline \multirow[t]{2}{*}{$\mathrm{E}$} & severe & 100 & 1.79 & 2.11 & 1.00 & $1-1$ & \multirow[t]{2}{*}{0.000} & \multirow[t]{2}{*}{ HS } \\
\hline & Mild & 100 & 6.88 & 3.41 & 7.00 & $5-9.75$ & & \\
\hline \multirow{2}{*}{ D DIMER } & severe & 99 & 3813.91 & 10046.80 & 1008.00 & $445-2601$ & \multirow[t]{2}{*}{0.000} & \multirow[t]{2}{*}{ HS } \\
\hline & Mild & 100 & 521.78 & 637.04 & 319.00 & $188.25-563.75$ & & \\
\hline \multirow[t]{2}{*}{ CRP } & severe & 100 & 276.29 & 281.68 & 199.50 & $88.25-370$ & 0.000 & HS \\
\hline & Mild & 100 & 65.23 & 82.72 & 36.00 & $13-84.75$ & & \\
\hline FERRITI & severe & 100 & 1275.66 & 2107.95 & 657.50 & $456.75-977$ & 0.000 & $\mathrm{HS}$ \\
\hline $\mathrm{N}$ & Mild & 100 & 533.94 & 769.67 & 319.00 & $154.5-615$ & & \\
\hline LDH & severe & 100 & 399.93 & 293.84 & 377.50 & $187-563.75$ & 0.058 & NS \\
\hline & Mild & 100 & 319.41 & 143.31 & 285.50 & $234.5-375$ & & \\
\hline AST & severe & 100 & 60.22 & 63.09 & 41.00 & $27-62$ & 0.031 & Sig \\
\hline & Mild & 100 & 43.04 & 31.02 & 34.00 & $21.25-51$ & & \\
\hline ALT & severe & 100 & 39.81 & 28.41 & 32.00 & $20-48$ & 0.190 & NS \\
\hline & Mild & 100 & 35.09 & 25.76 & 27.00 & $16-44.25$ & & \\
\hline
\end{tabular}

a) Hemogram

Hemoglobin levels were found to be lower in those with mild disease (mean of $11.79 \mathrm{~g} / \mathrm{dl}$ ) as against those with severe disease (mean 12.01\%) p value 0.303 which was not found to be significant.

Platelet counts did not show much difference between 2 groups (2.47 vs 2.39) and was not significant.

The mean total counts were 8741 cells $/ \mathrm{mm}^{3}$ for those with mild disease as against 8970 cells $/ \mathrm{mm}^{3}$ for those with severe disease ( $\mathrm{p}$ value 0.207 ) which was not found to be significant.
Neutrophilia was noted in both groups with a mean of $72.59 \%$ among those with mild disease and $74.89 \%$ among those with severe disease, which was not found to be significant.

Lymphocytopenia was noted in both groups with a mean of $17.84 \%$ and $15.72 \%$ respectively, which was not significant.

There was a significant difference in the basophil count (mean 2.35 and 5.92) among those with mild and severe disease respectively; as also with the eosinophil count (mean 6.88 and 1.79) for those with mild and severe disease; both were highly significant ( $\mathrm{p}$ value 0.000 ). 
ROC Curve demonstrated a sensitivity 92\%, specificity $37 \%$ (AUC- 0.854 , p value 0.000 ) with a cut off of $0-1 \%$ for basophils and sensitivity $92 \%$, specificity $45 \%$, (AUC- 0.880 , p value 0.000 ) with a cut off of $1-6 \%$ for eosinophils (Table 3 ).

\section{b) Liver enzymes}

Transaminases (AST/ALT) were elevated in COVID positive patients; however, AST levels showed a significant difference between the 2 groups (mean 43.06 and 60.22; p value 0.031). ROC Curve demonstrated a sensitivity $64 \%$, specificity $45 \%$, (AUC- $0.588, \mathrm{p}$ value- 0.031 ) with a cut off of 0 35IU/L for AST levels (Table 3).

\section{c) Inflammatory and biochemical markers}

Coagulation tests suggested that D-dimer were increased in COVID-19 patients, and the increase was more pronounced in those with severe disease (mean $3813.91 \mathrm{ng} / \mathrm{ml}$ ) than in the mild disease group (mean $521.78 \mathrm{ng} / \mathrm{ml}$ ) $\mathrm{P}<0.000$ was found to be highly significant. An ROC curve demonstrated sensitivity 96\%, specificity 65\%, (AUC-0.81, p value-0.000) with a cut off of $0-243 \mathrm{ng} / \mathrm{ml}$ for $\mathrm{D}$ dimer levels (Table 3).

The levels of CRP were higher in those with severe disease as compared to the mild disease group (mean 276.29 and 65.23). Also, Ferritin levels were markedly increased severe disease patients (mean 1275.66 and 533.94); both were statistically significant with $\mathrm{p}$ value 0.000 .

ROC Curve demonstrated a sensitivity of 97\%, specificity $75 \%$ (AUC- 0.735 , p value -0.000 ) with cut off of $13-150 \mathrm{ng} / \mathrm{ml}$ for ferritin levels.

ROC Curve demonstrated a sensitivity of $100 \%$ specificity $84 \%$ (AUC -0.85 , p value-0.000) with a cut off of $0-5 \mathrm{mg} / \mathrm{l}$ for CRP levels (Table 3 ).

Lactate dehydrogenase (LDH) levels were higher than those in regular patients, however, no significant difference was noted between both groups.

ROC Curve demonstrated a sensitivity 69\%, specificity $66 \%$, (AUC 0.578 , p value 0.058 ) with a cut off of $0-250 \mathrm{IU} / \mathrm{L}$ for $\mathrm{LDH}$ levels.

Table 4: Distribution based on Neutrophil-Lymphocyte Ratio (NLR), Platelet-Lymphocyte Ratio (PLR), Lymphocyte-Monocyte Ratio (LMR)

\begin{tabular}{|c|c|c|c|c|c|c|c|c|c|}
\hline \multirow{2}{*}{\multicolumn{2}{|c|}{ Group }} & \multirow{3}{*}{$\begin{array}{l}\mathrm{N} \\
\\
99 \\
\end{array}$} & \multirow{3}{*}{$\begin{array}{l}\text { Mean } \\
7.53 \\
\end{array}$} & \multirow{3}{*}{$\begin{array}{c}\text { Std. } \\
\text { Deviation } \\
6.50\end{array}$} & \multirow{4}{*}{$\begin{array}{c}\begin{array}{c}50 \text { th } \\
\text { (Median) }\end{array} \\
5.3 \\
5.3\end{array}$} & \multirow{2}{*}{\multicolumn{2}{|c|}{ Percentiles }} & \multirow{4}{*}{$\begin{array}{c}\text { Mann } \\
\text { Whitney test } \\
\text { p value }\end{array}$} & \multirow{3}{*}{ NS } \\
\hline & & & & & & & & & \\
\hline NLR & severe & & & & & \multirow{2}{*}{$\begin{array}{l}25 \text { th } \\
3.0 \\
27\end{array}$} & $\begin{array}{c}75 \text { th } \\
9.3 \\
\end{array}$ & & \\
\hline & Mild & 100 & 6.71 & 5.75 & & & 8.3 & & \\
\hline \multirow[t]{2}{*}{ PLR } & severe & 99 & 21599.83 & 17143.73 & 16000.0 & 9565.2 & 29000.0 & \multirow[t]{2}{*}{0.674} & NS \\
\hline & Mild & 100 & 22132.76 & 20805.74 & 15479.2 & 7904.2 & 28562.5 & & \\
\hline \multirow{2}{*}{$\begin{array}{l}\text { LMR } \\
(\mathrm{L} \backslash \mathrm{M})\end{array}$} & severe & 100 & 4.35 & 4.94 & 3.0 & 1.7 & 5.0 & \multirow[t]{2}{*}{0.894} & $\mathrm{NS}$ \\
\hline & Mild & 99 & 4.42 & 4.27 & 3.0 & 1.6 & 5.5 & & \\
\hline
\end{tabular}

In our study, none of the ratios predict the severity of disease (Table 4).

\section{DISCUSSION}

Coronavirus (COVID-19) is an emerging infectious respiratory disease. In the absence of an effective definitive treatment $(8,9)$, it is imperative to identify the markers that can help monitor the progression of disease and in early management of patients. The present study aimed to investigate the relationship between hematological parameters and disease severity in COVID-19 patients and the results revealed that Ferritin, D-dimer, CRP levels along with basophil counts were significantly elevated among those with severe disease as against those with mild disease.

As lymphocytes are virus-fighting effector cells, most viral infections in humans cause lymphocytosis (10). The coronavirus family however caused lymphocytopenia in infected patients in some studies $(11,12)$, the mechanism probably being direct attack of coronavirus on lymphocytes or by immunemediated apoptosis of lymphocytes (13-15). Our study also noted lymphocytopenia in COVID infected patients.
Qin et al., reported that lymphopenia and an increased neutrophil-lymphocyte ratio were frequently observed in patients with severe COVID19 compared with those with mild disease (16).

Henry et al., in their study about the hematological parameters of COVID-19 patients (17) suggested that the more severe and deadly cases of the disease had higher WBC count and lower lymphocyte and PLT than the mild cases. In their study, CRP had also increased as an indicator of systemic inflammation in COVID-19 patients. In this regard, routine evaluation of hematological parameters, including PLR and NLR, was suggested as a prognostic predictor of COVID-19 patients (18). In our study however, PLR and NLR could not predict severity of disease.

In a meta-analysis conducted by Zeng et al., (19) to determine the association of inflammatory markers with the severity of COVID-19,16 studies comprising 3962 patients with COVID 19 were analyzed and it was found that patients with COVID-19 in the nonsevere group had lower levels for platelets, CRP, IL- 
6, ESR and serum ferritin compared to those in the severe group.

Najim et al., conducted a study on 130 COVID positive patients; 65 symptomatic and 65 asymptomatic. They noted a significant decrease in total leukocyte counts and lymphocytes (P-value 0.0001 and 0.0001 respectively), and a significant rise of LDH, D-Dimer, CRP, and Ferritin levels (Pvalue:0.004,0.002,0.001,0.0001 respectively) concluding that hematological parameters can be used as a predictor for severity of disease (20). The findings of their study were in agreement with those found in our study. Several studies have noted a high significant level of C-reactive protein, D-Dimer, and serum ferritin among the severe group (20-24).

In a study by Yuan et al., severe, and critically ill patients had elevated D-dimer and FDP levels which was in agreement with findings of our study. Based on these findings, it was noted that COVID-19 patients are in a hypercoagulable state and that plasma D-dimer and FDP levels might have the potential to guide treatment and evaluate prognosis. Additionally, it was found the CRP, PCT, ESR, FER and LDH were higher in severe and critically ill patients than in regular patients, suggesting that the inflammatory response was more prominent in severe and critically ill patients as also noted by Yuan et al., (25).

Our study had a few limitations. Limited to retrospective analysis, the dynamic data collection of the patients was not comprehensive, and the changes in hematological parameters over the duration of hospital stay was not analyzed.

\section{CONCLUSION}

From our study we could conclude that inflammatory markers were positively correlated to the severity of covid infection, thus highlighting their role in the early diagnosis of the disease, considering the information they provide to physicians regarding the inflammatory process and in monitoring the progression to severity of the disease. Accordingly, hematological parameters and inflammatory biomarkers in the COVID-19 patients potentially act as independent factors and affect the disease prognosis. Hence, conducting further studies that can help with risk stratification is the need of the hour.

\section{CONFLICT OF INTEREST}

Authors declare that there is no conflict of interest.

\section{REFERENCES}

1. Zhu, N., Zhang, D., Wang, W., Li, X., Yang, B., Song, J., et al.,China Novel Coronavirus Investigating and Research Team. A Novel Coronavirus from Patients with Pneumonia in China, 2019. N Engl J Med. 2020 Feb 20; 382(8): 727733.

2. Coronavirus disease 2019 (COVID-19): current literature and status in India. [Apr;2020]
3. Shi, H., Han, X., Jiang, N., Cao, Y., Alwalid, O., Gu, J., et al., Radiological findings from 81 patients with COVID-19 pneumonia in Wuhan, China: a descriptive study. Lancet Infect Dis. 2020 Apr; 20(4): 425-434.

4. Adhikari, S. P., Meng, S., Wu, Y. J., Mao, Y. P., Ye, R. X., Wang, Q. Z., et al., Epidemiology, causes, clinical manifestation and diagnosis, prevention and control of coronavirus disease (COVID-19) during the early outbreak period: a scoping review. Infect Dis Poverty. 2020 Mar 17; 9(1): 29.

5. Li, Q., Guan, X., Wu, P., Wang, X., Zhou, L., Tong, Y., et al., Early transmission dynamics in Wuhan, China, of novel coronavirus-infected pneumonia. N Engl J Med. 2020; 382: 1199-1207.

6. Novel coronavirus infected pneumonia treatment schemeSixth edition. National Health Commission of the People's Republic of China. 2020.

7. Guan, W. J., Ni, Z. Y., Hu, Y., Liang, W. H., Ou, C. Q., He, J. X., et al., Clinical characteristics of coronavirus disease 2019 in China. N Engl J Med. 2020; 382: 1708-1720.

8. Li G., De Clercq, E. Therapeutic options for the 2019 novel coronavirus (2019-nCoV) Nat Rev Drug Discov. 2020; 19(3): 149-150.

9. Russell, C. D., Millar, J. E., Baillie, J. K. Clinical evidence does not support corticosteroid treatment for 2019-nCoV lung injury. Lancet. 2020; 395(10223): 473-475.

10. Zhu, Y., Cao, X., Tao, G., Xie, W., Hu, Z., Xu, D. The lymph index:a potential hematological parameter for viral infection. Int J Infect Dis. 2013; 17(7): e490 e493493.

11. Rabaan, A. A., Al-Ahmed, S. H., Haque, S., Sah, R., Tiwari, R., Malik, Y.S., et al., SARS-CoV-2, SARS-CoV, and MERS-COV: a comparative overview. Le infezioni in medicina. 2020; 28(2): 174-184.

12. Al-Tawfiq, J. A., Hinedi, K., Abbasi, S., Babiker, M., Sunji, A., Eltigani, M. Hematologic, hepatic, and renal function changes in hospitalized patients with Middle East respiratory syndrome coronavirus. Int J Lab Hematol. 2017; 39(3): 272-278.

13. Panesar, N. S. What caused lymphopenia in SARS and how reliable is the lymphokine status in glucocorticoid-treated patients? Med Hypotheses. 2008; 71(2): 298-301.

14. He, Z., Zhao, C., Dong, Q., Zhuang, H., Song, S., Peng, G., etal., Effects of severe acute respiratory syndrome (SARS) coronavirus infection on peripheral blood lymphocytes and their subsets. Int J Infect Dis. 2005; 9(6): 323-330.

15. Chu, H., Zhou, J., Wong, B. H., Li, C., Chan, J. F., Cheng, Z.S., et al., Middle East respiratory syndrome coronavirus efficiently infects human primary $\mathrm{T}$ lymphocytes and activates the extrinsic and intrinsic apoptosis pathways. J Infect Dis. 2016; 213(6): 904-914.

16. Qin, C., Zhou, L., Hu, Z., Zhang, S., Yang, S., Tao, Y., et al., Dysregulation of immune response in patients with COVID-19 in Wuhan, China. Clin Infect Dis. 2020

17. Henry, B. M., de Oliveira, M. H. S., Benoit, S., Plebani, M., Lippi, G. Hematologic, biochemical and immune biomarker abnormalities associated with severe illness and mortality in coronavirus disease 2019 (COVID-19): a meta-analysis. Clin Chem Lab Med. 2020 Jun 25; 58: 1021-1028.

18. Zhou, F., Yu, T., Du, R., Fan, G., Liu, Y., Liu, Z., et al., Clinical course and risk factors for mortality of adult inpatients with COVID-19 in Wuhan, China: a retrospective cohort study. Lancet. 2020.

19. Zeng, F., Huang, Y., Guo, Y., Chen, X., Xiao, L., Deng, G.Association of inflammatory markers with the severity of COVID- 19: a meta-analysis. Int J Infect Dis. 2020; 96: 467474.

20. Najim, R. H., Kadhim, S. R. Biochemical and hematological parameters as a predictor for COVID -19 infection in 65 patients diagnosed by real time -PCR in Kirkuk city. SRP. 2020; 11(5): 797-799

21. Wan, S., Xiang, Y., Fang, W., Zheng, Y., Li, B., Hu, Y., et al., Clinical features and treatment of COVID-19 patients in Northeast Chongqing. J Med Virol 2020; 0-1. 
22. Zhang, G., Hu, C., Luo, L., Fang, F., Chen, Y. F., Li, J., et al., Clinical features and outcomes of 221 patients with COVID-19 in Wuhan, China. Med Rxiv. 2020

23. Zhao, W., Zha, X., Wang, N., Li, D.Z., Li, A., Yu, S. Clinical characteristics and durations of hospitalized patients with COVID- 19 in Beijing: a retrospective cohort study. Med R. 2020; 21: 1-9.

24. Zhang, J. J., Dong, X., Cao, Y. Y., Yuan, Y. D., Yang, Y. B., Yan, Y. Q., et al., Clinical characteristics of 140 patients infected with SARS- CoV-2 in Wuhan, China. Allergy Eur J Allergy Clin Immunol. 2020; 1-12.

25. Yuan, X. H., Huang, W. L., Ye, B., Chen, C.R., Huang, R. F., Feng, Wu., et al., Changes of hematological and immunological parameters in COVID19patients. International Journal of Hematology. 2020; 112: 553-559. 